\title{
Multi-objective optimal allocation of water resources in Yangchangwan mining area based on ecological priority
}

\author{
Zhen Zhang ${ }^{1}$, Panyue Zhang ${ }^{2, *}$, and Guangming Zhang ${ }^{1}$ \\ ${ }^{1}$ Renmin University of China, Beijing, 100872, China \\ ${ }^{2}$ Beijing Forestry University, Beijing, 100083, China
}

\begin{abstract}
With the development of mining area economy and the adjustment of industrial structure from traditional heavy industry to hightech industry, the supply and demand structure of water resources has changed significantly, and the ecological damage in mining area make the ecological water consumption increase significantly. This paper summarizes the water supply of surface water, groundwater, mine drainage and reclaimed water, as well as all kinds of water demand. Based on the principle of ecological priority, a multi-objective optimal allocation model for the coordinated development of ecological environment, social economy and water resources in Yangchangwan mining area was constructed. The results show that the multi-objective optimal allocation model well coordinated the social and economic development goals and resource saving goals, and the optimization scheme ensured that the water demand satisfaction of each water sector reached $100 \%$. On the one hand, it can provide technical support for the mining area to realize the green water and green mountains pattern as soon as possible, on the other hand, it can also provide reference for water resources management in other similar areas.
\end{abstract}

\section{Introduction}

The research on optimal allocation of water resources (WROA) began in the 1950s. In recent decades, it has become the research focus of more and more scholars. In order to promote the optimal allocation and effective utilization of limited water, mathematical methods are adopted[1], including linear programming (LP), dynamic programming (DP), nonlinear programming (NLP), goal programming (GP) and multi-objective programming (MOP) [2]. Among them, multi-objective optimal allocation model can comprehensively consider the ecological and economic benefits, so it can get a more scientific water resources allocation scheme.

Yangchangwan Coal Mine is located in Ningdong Town, Lingwu City, Ningxia Hui Autonomous Region. The coal mine is one of the 13 large-scale coal bases in Ningdong and one of the high-quality coal development bases in China. The ecological environment of the mining area is extremely fragile, which belongs to the coexistence area of water resource-

*Corresponding author: panyue_zhang@bjfu.edu.cn 
induced water shortage and water quality-induced water shortage. The ecological damage caused by mining is in urgent need of repair. Water resources is an important natural resource in the process of industrial transformation and upgrading and ecological environment construction. With the long-term exploitation of deep well, the water resources decline, and its underground water can no longer meet the production requirements of the mining area development needs. As an unconventional water resource, mine water should be consider as a new water source to solve the problem of ecological water shortage in mining area. Based on the ecological concept, the multi-objective optimal allocation of water resources should adhere to the principle of "giving priority to the ecological environment and domestic water demand, ensuring the basic industrial water demand".

\section{Construction of multi-objective optimal allocation model}

The objective function of the multi-objective optimal allocation model is multiple, which constitutes a vector optimization problem. The general formula of the model is as follows:

$$
\begin{gathered}
\text { opt } F(x)=\left[f_{1}(x), f_{2}(x), \ldots, f_{p}(x)\right]^{T} \\
\text { s.t. } g_{i}(x) \leq b_{i}, i=1,2, \ldots, m
\end{gathered}
$$

where $x$ is decision variables; $f_{P}(x)$ is objective function; $g_{i}(x)$ is constraint condition; $p$ is the number of objective functions; $m$ is the number of constraints.

The decision variable $x$ is determined by different water sources and water use departments. The majority of domestic water is taken from groundwater, so other water supply sources are not considered. Secondly, industrial water is not supplied by groundwater.

\subsection{Objective function}

The multi-objective optimal allocation model of water resources seeks to maximize the comprehensive benefits of ecological environment, economy and society. Therefore, the objective function is divided into three objectives: ecological environment benefit, economic benefit and social benefit.

(1) Environmental benefit target

The ecological environmental benefits can be reflected by the sewage discharge. The smaller the value, the smaller the pollutant discharge, the greater the ecological benefit. Generally, it is measured by the amount of important pollutants, such as Eq. (2):

$$
\operatorname{minf}_{1}(x)=0.01 d_{j} p_{j} \sum_{j=1}^{J} \sum_{i=1}^{I} x_{i j}
$$

where $d_{j}$ is discharge concentration of important pollutants in sewage discharged by $j$ user $(\mathrm{mg} / \mathrm{L})$, chemical oxygen demand (COD) was used to measure the model; $p_{j}$ is sewage discharge coefficient of $j$ user.

(2) Economic benefit target

The economic benefit can be expressed by the direct economic benefit brought by water supply, as shown in Eq. (3):

$$
\max _{2}(x)=\sum_{j=1}^{J} \sum_{i=1}^{I}\left(b_{i j-} c_{i j}\right) x_{i j} \alpha_{i j} \beta_{i j}
$$

where $x_{i j}$ is $i$ water supply to $j$ water sector; $b_{i j}$ is $i$ water supply benefit coefficient (RMB yuan $/ \mathrm{m}^{3}$ ) of water source to $j$ water sector; $c_{i j}$ is the cost coefficient of water supply from $i$ source to user (RMB yuan $/ \mathrm{m}^{3}$ ); $\alpha_{\mathrm{ij}}$ is supply sequence coefficient of water supply from source 
$i$ to user $j ; \beta_{i j}$ is water equity coefficient of user $j$.

(3) Social benefit target

Social benefits are generally reflected indirectly by the minimum value of regional water shortage, as shown in Eq. (4):

$$
\min _{3}(x)=\sum_{j=1}^{J}\left(D_{j}-\sum_{i=1}^{I} x_{i j}\right)
$$

where $D_{j}$ is the water demand of $j$ user.

\subsection{Constraints}

(1) Water supply constraints

The amount of water supplied by a source should not exceed its available amount, as shown in Eq. (5):

$$
\sum_{j=1}^{J} x_{i j} \leq W_{i}
$$

where $W_{i}$ is the available water supply of $i$ water source.

(2) Water demand constraints

The water supply shall not be less than the minimum water demand of users, minimum water demand is generally calculated as $90 \%$ of the water demand[3], as shown in Eq. (6):

$$
D_{j_{\min }} \leq \sum_{i=1}^{I} x_{i j} \leq D_{j}
$$

where $D_{j}-\mathrm{t}$ is the water demand of $\mathrm{j}$ water users; $D_{\text {jmin }}$ is the minimum water demand of water users.

(3) Non-negative constraint

The value of water supply must not be negative, as shown in Eq. (7):

$$
x_{i j} \geq 0
$$

\subsection{Model solving method}

From Section 2.1 and 2.2, the objective function and constraints of water resources optimization model can be obtained. Fgoalatain function optimization toolbox in MATLAB is used in order to get the solution of the multi-objective optimal allocation model. The optimal configuration results of different planning years can be obtained. The method of finding the minimum value of Fgoalattain function is as follows, as shown in Eq. (8):

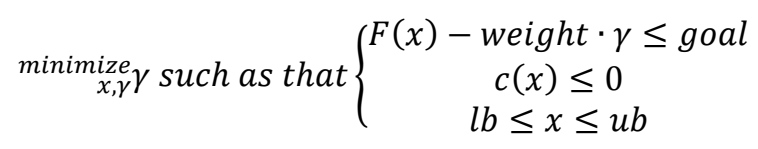

where weight and goal are vectors, $F(x)$ and $c(x)$ are functions that return vectors, and $l b$, $x$ and $u b$ can be vectors or matrices. Given the objective function, constraint conditions and weight, the function starts from the initial value $x_{0}$ to find $x$ to make the objective function reach the goal specified by goal. It is a conventional optimization method with the advantages of small amount of calculation and fast convergence speed. 


\section{Application examples}

\subsection{Analysis of water supply and demand balance in Yangchangwan}

Yangchangwan mining area is located in Lingwu City, Ningxia Province. The available water sources are from local groundwater, external groundwater, external surface water and mine water. In terms of resource supply, mine water as a water resource with mining characteristics, its reasonable recycling is particularly important.

The resource quantity of mine water can be estimated by water yield coefficient and coal production[4]. The amount of reclaimed water is based on the statistical data of Yangchangwan mining area. The monthly reference crop water requirement was calculated by Penman-Monteith formula recommended by FAO[5]. According to the meteorological data of Yangchangwan area from 1968 to 2018, the actual water demand of each stage was obtained by using the crop coefficient method, and the total ecological water demand was finally obtained. Analysis of supply and demand balance is shown in Table 1.

Table 1. Analysis of supply and demand balance of water resources in Yangchangwan $\left(10^{4} \mathrm{~m}^{3}\right)$.

\begin{tabular}{ccc}
\hline & Ecological & 60.31 \\
water demand & Industrial & 300 \\
& Living water & 31.16 \\
& Subtotal of water demand & 391.47 \\
\cline { 2 - 3 } & mine water & 594.12 \\
Water supply & recycled water & 24.94 \\
& surface water & 100 \\
& groundwater & 50 \\
& Subtotal of water supply & 769.06 \\
\hline
\end{tabular}

\subsection{Parameter acquisition}

(1) Water supply order coefficient $\alpha_{i j}$ and user equity coefficient $\beta_{i j}$

The order coefficient of water supply $\alpha_{i j}$ reflects the priority of water supply. The allocation of water resources in the mining area follows the principle of making full use of reclaimed water and mine drainage water, giving priority to surface water and slowing down groundwater supply. The order of water supply is reclaimed water $>$ mine water $>$ surface water $>$ groundwater. The water supply coefficients determined by binary comparison method are $0.40,0.33,0.17$ and 0.10 respectively.

The user equity coefficient $\beta_{i j}$ reflects the priority of water supply. According to the principle of ecological priority, the mining area follows the principle of giving priority to the allocation of ecological and domestic water demand, and the water equity coefficients of life, ecology and industry are determined as $0.35,0.35$ and 0.3 respectively.

(2) Benefit coefficient and cost coefficient of water supply

Table 2. Value of benefit coefficient and cost coefficient.

\begin{tabular}{cccc}
\hline & Living water & Ecological water & Industrial water \\
\hline Benefit coefficient $\left(\mathrm{RMB} \mathrm{Yuan} / \mathrm{m}^{3}\right)$ & 550 & 550 & 635 \\
Cost coefficient (RMB Yuan $\left./ \mathrm{m}^{3}\right)$ & 3.78 & 1.8 & 6.81 \\
Discharge coefficient & 0.8 & 0.1 & 0.7 \\
COD concentration (mg/L) & 20 & 30 & 120 \\
\hline
\end{tabular}

The selection of benefit parameters and cost parameters refer to the previous research results[3,67]. By selecting the benefit coefficient of water supply in nearby areas, the model can be more typical and representative. Combined with the basic theory of uncertainty, the economic objective of optimal allocation of water resources in the process of water supply and consumption is determined. The value range of benefit parameters and cost coefficient is shown in Table 2. 
(3) Upper and lower limits of water demand

The upper limit of water demand is the maximum water demand of water sector, and the lower limit is based on the actual situation of the study area. In order to promote the ecological environment construction in the mining area, improve the ecological environment and give priority to ensuring the ecological water demand, the guarantee rate is $100 \%$; in order to ensure the normal demand of people's life, the guarantee rate of living water demand is $100 \%$; and the guarantee rate of industrial water demand is $90 \%$.

\subsection{Result analysis}

Through the function analysis of model and the parameter selection principle described in 2.3 , the optimization toolbox of MATLAB software is used to solve the model, so as to obtain the solution of the optimal allocation model of water resources in the mining area. In order to show the optimization results of water resources in the mining area more intuitively, draw Figure 1 for analysis. As can be seen from Figure 1:

(1) Industrial water is the sector with the largest water demand. As shown in Figure 1, the water demand of the industrial sector accounts for about $80 \%$ of the total water demand. If the industrial water consumption reduced, the reduction of total water demand will be most significant. Therefore, optimizing the industrial structure, improving the efficiency of industrial water use and water saving in mining area are the top priority to improve the utilization of water resources.

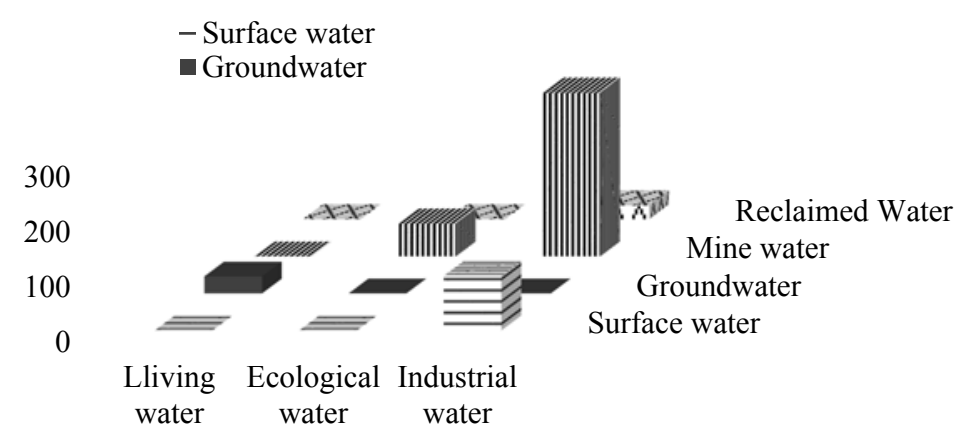

Fig. 1. Histogram of water resources allocation in Yangchangwan mining area.

(2) Ecological water is mainly mine water after treatment, which can avoid occupying surface water and groundwater resources. Sufficient mine water can fill the water demand gap in the face of mine area restoration in arid areas. Therefore, optimizing mine water treatment technology and solving the technical problems of mine water reuse are the basis to ensure the ecological restoration of the mining area. Domestic water mainly comes from groundwater.

(3) From the analysis of the source of industrial water, it can be predicted that increasing the reuse of mine water indirectly saves surface water resources, which is in line with the concept of water saving and full utilization of water resources. Although the treatment of mine water and reclaimed water cannot directly get high-quality water resources, it can be replaced by the application in other water departments, such as coal washing, irrigation water and so on, so as to provide support for water-saving work.

As described by the model, the results obtained in this paper not only meet the constraints of water supply, but also ensure the comprehensive optimization of economic and ecological benefits, which can be used as a scientific decision-making basis for water resources allocation planning in Yangchangwan mining area. Also, it can also provide reference for mine water treatment and recycling, and comprehensive water-saving work in mining area. 


\section{Conclusion}

The multi-objective optimal allocation model can reflect the multi objectives in complex environment. In this paper, it is applied to the field of optimal allocation of water resources in mining area which is in urgent need of ecological restoration. In the construction and solution of the model, it objectively reflects the essential issues and has significant advantages over other simple models.

(1) Through the case study of water resources optimal allocation in Yangchangwan mining area, it shows that the multi-objective optimal allocation model has good applicability in the problem of water resources optimal allocation in mining area, and it has strong practicability to use MATLAB tool to solve it quickly.

(2) The results show that, the industrial water consumption satisfaction of the configuration scheme reaches $140 \%$, so the scheme can accommodate the growth of industrial water demand with the rise of industrial output value. The treatment and utilization of mine water is the basis of ensuring sufficient industrial water.

(3) The allocation result reflects the allocation principle of giving priority to ecological and domestic water, and ensuring the stable development of industry, which is conducive to improving the ecological environment and promoting the stable development of economy and society, and also provides reference for water resources management in Yangchangwan mining area.

\section{Acknowledgement}

Thanks to the support of key research and development project (2017YFC0504400), ecological security technology of coal base in Northwest Arid Desert Area: project 5: Research on Key Technologies of water resources protection and comprehensive utilization in mining area.

\section{References}

1. M. Heydari, F. Othman, and K. Qaderi, Developing Optimal Reservoir Operation for Multiple and Multipurpose Reservoirs Using Mathematical Programming, Math. Probl. Eng., vol. 2015, p. 435752, 2015.

2. A. A. Musa, Goal programming model for optimal water allocation of limited resources under increasing demands, Environ. Dev. Sustain., 2020.

3. X.Bai, F.Q.Bai, Study on water resources planning of Fengfeng mining area based on ecological concept, Hebei University of technology, 2019.(in Chinese)

4. F.L.Wang, Study on Optimization of calculation method of water inflow in different production periods of mine, Coal science and technology, Vol. 47, No. 12, pp. 177 - 183, 2019.(in Chinese)

5. L. P. R. G. Allen, Crop evapotranspiration, Guidelines for crop water requirements. FAO 56, 1998.

6. M. Li and P. Guo, A multi-objective optimal allocation model for irrigation water resources under multiple uncertainties, Appl. Math. Model., 2014.

7. M. Li, Q. Fu, V. P. Singh, D. Liu, T. Li, and Y. Zhou, Managing agricultural water and land resources with tradeoff between economic, environmental, and social considerations: A multi-objective non-linear optimization model under uncertainty, Agric. Syst., 2020. 